\title{
NOTAS \\ NUEVOS GENTILICIOS EN EL ESPAÑOL COLOMBIANO
}

El proceso lingüístico de la sufijación ${ }^{1}$ amplía constantemente la riqueza léxica del español. En el español hispanoamericano, dada su extensión geográfico-étnica, se ha formado una serie de voces y gentilicios nuevos por medio de la sufijación. Entre los sufijos del español, los gentilicios pertenecen al grupo general de sufijos transformativos ${ }^{2}$.

Los sufijos gentilicios del español general más usuales y comunes son: -ano (bogotano, colombiano, michoacano y veracruzano); -ense (atlanticense [Colom.], coahuilense); - eño (antigüeño [Guat.], cruceño); -ero (cartagenero y habanero).

Además de algunos gentilicios como guatemalteco y yucateco usuales en América hispánica, el nuevo gentilicio mesoamericano -eco (-teco) se halla con más frecuencia en Centroamérica ${ }^{3}$ y México: acajuteco (ca), natural de Acajutla, Salvador; chichicasteco (ca), natural de Chichicastenango, Guatemala; guanacasteco ( $c a$ ), natural de Guanacaste, Costa Rica; mazateco (ca), natural de Mazatlán, México, o Mazatenango, Guatemala.

En el caso de -eco(-teco), préstamo del náhuatl, el gentilicio mismo es nuevo. Y aunque es difícil determinar si los gentilicios con esa terminación son préstamos directos, la desinencia se añade a la lista de sufijos con función gentilicia en el español mesoamericano.

En general, en Colombia se encuentran los sufijos gentilicios tradicionales del castellano: -ano. Bogotano (na); tunjano (na), natural de Tunja, capital del departamento de Boyacá; atlanticense, natural del departamento del Atlántico; caldense, natural del departamento de Caldas.

-eño: abajeño. Aunque en Puerto Rico y la América Meridional se dice del que procede de las tierras o costas bajas, o de los puertos de mar $^{4}$, en

${ }^{1}$ Roger L. Hadlich distingue entre la morfología de inflexión y la de la derivación: "Derivational morphology treats the base forms of words to which endings must be attached and examines what constituents make up these bases and how they are combined" (A transformational grammar of Spanish, New Jersey, 1971, p. 197).

2 Transformativos son los aumentativos (-azo, -ón, -ote), los diminutivos (ejo, -ico, -in, -ito), que modifican el significado original de la raíz. Se destacan los que denotan pertinencia y relación (-uno), profesión (-ero, -ista), lugar y abundancia $(-a d a,-a l)$ calidad (-esco, -oso) y filosofía (-ismo) (véase José A l.minxy Bol.ufre. Tratado de la formación de palabras en la lengua castellana. La derización y la composición. Estudio de los sufijos y prefijos empleados en una y otra, Madrid, 1920.

${ }^{3}$ Excluimos a Panamá porque la influencia lingüístico-cultural no se había extendido a esa región de América; también porque Panamá formó parte de Colombia hasta 1914 y todavía comparte con ésta rasgos lingǘsticos y culturales. Además, a diferencia de los cinco países centroamericanos y México, el sufijo -eco se encuentra en Panamá principalmente con el significado de defecto o despectivo, e.g., noneco, 'bobalicón'.

4 Marcos A. Morfnigo, Diccionario manual de americanismos, Buenos Aires, 1966, p.. 17 . 
México y Colombia es un "gentilicio que aplican a los habitantes y cosas de las provincias del norte los que viven en el sur"'s. Antioqueño, natural del departamento de Antioquia; arribeño, "aplícase por los habitantes de las costas al que procede de las tierras altas"6.

-ero: Barranquillero. Natural de Barranquilla, capital de departamento del Atlántico.

-és: Cundinamarqués. Natural del departamento de Cundinamarca.

Pero hay voces colombianas cuyo sufijo da un gentilicio nuevo. Así -ejo en popayanejo (ja), natural de Popayán, ciudad colonial y capital del departamento del Cauca. Este sufijo forma derivados nominales, casi todos sustantivos, de significación diminutiva con cierto matiz despectivo (animalejo y caballejo, calleja y capeja). Pero popayanejo carece de connotación peyorativa. Además, es posible que la función nueva encuentre apoyo fonético en otro adjetivo gentilicio que tampoco es despectivo, como barrancabermejo, natural de la ciudad petrolera de Barrancabermeja, aunque en este caso la desinencia no funciona morfológicamente como sufijo.

-ista en tomista, natural de Santo Tomás. El diccionario académico no registra otra acepción que la adjetiva referida a la doctrina tomista. En su Cuestionario lingüistico hispanoamericano (Buenos Aires, 1943, p. 73), Tomás Navarro incluye el sufijo -ista en la lista de sufijos gentilicios con penquista aunque no da el lugar de origen, que puede ser Pencas, Péncamo o Penco, ciudad de Chile cerca de Concepción. O bien puede ser que penquista se refiera al natural que viene de un lugar muy poblado de la provincia de Córdoba, Argentina. No obstante, el gentilicio en -ista, que encontramos también en la voz brasileña santista (de la ciudad de Santos), es innovación en el español colombiano.

El sufijo -oso, que por lo común se añade a raíces sustantivales y verbales para formar adjetivos que expresan la posesión de la cualidad del objetivo primitivo, como cariñoso y orgulloso, aparece en el gentilicio reinoso(sa), natural del Reino, es decir del departamento de Boyacá.

El sufijo despectivo -ucho, a veces diminutivo y jocoso (aguilucho, papelucho, malucho), aparece en maracucho (ucha), natural de Maracaibo, ciudad situada a orillas del mismo lago, cerca de la frontera colombiana.

El sufijo -uno, que generalmente forma derivados que denotan propiedad o relación (perruno y vacuno), se encuentra en paramuno (na), natural o habitante de los páramos, o sea de las cordilleras de Colombia; valluno (na), natural del departamento del Valle del Cauca (vallecaucano). Es posible que el uso gentilicio de -uno sea una extensión colombiana del uso normal, 'relativo o propio del lugar denominado por la raíz'.

Pastuso (sa), natural de Pasto, capital del departamento de Nariño, en donde la desinencia - uso no parece ser más que la sustitución ortográfica de $z$ por $s$. Este sufijo, de significación despectiva, aparece en los sustantivos carnuza y gentuza y adjetivos lechuzo y pajuzo. La función gentilicia es completamente innovadora en el colombiano.

Samario (ria) es en Colombia el natural de Santa Marta, capital del

${ }^{5}$ Leonardo Tascon, Diccionario de provincialismos y barbarismos del Valle del Cauca Bogotá, s.f., p. 1l. La voz existente en otros países de la América meridional y Puerto Rico.

${ }_{6}$ Mario Alario di Filuppo, Lexicón de colombianismos, Cartagena, 1964, p. 19. Se encuentran también en casi todos los países hispanos de América. 
departamento atlántico del Magdalena. -ario indica'lo que pertenece a alguna cosa o hace relación a ella: fraccionario, ordinario y penitenciario'?

Este sufijo se encuentra en los adjetivos de origen latino que denotan relación, calidad o pertenencia: cesario, trinitario, Cesario, de CESARIUM, se refería al natural de las tierras que pertenecían a César. Los cesarios actuales de Colombia vienen del departamento atlántico del César. Lo novedoso en samario, no obstante, es el resultado fonético al aplicarse-ario a Santa Marta y la vitalidad de -ario como sufijo gentilicio en el español colombiano.

Además de estos nuevos usos gentilicios, hay en el español colombiano dos nuevas voces que carecen de sufijos: paisa, natural del departamento actual de Antioquia y de los de Quindío y Risaralda, que pertenecían al antiguo departamento de Antioquia; antioqueño en general. Paisa (de uso casi general en América como apócope de paisano ${ }^{8}$ ) se refería al campesino y por broma a los antioqueños. Pocos colombianos lo emplean jocosamente.

Rolo (la) se emplea para referirse a los naturales y vecinos de Bogotá. Morínigo (op. cit., p. 568) indica que en Colombia rolo se refiere a un rodillo de imprenta, pero Flórez documenta dos significados en diferentes regiones: 'hombre grueso y pequeño' en Puerto Berrío, 'hombre muy bajo' 9 en Betania. Antes los costeños le llamaban rolo al hombre que venía de las tierras muy frías a pasear en las zonas tropicales. Es probable que el gentilicio, rolo, sea una extensión metafórica de las tres definiciones documentadas, o una especificación de la definición anterior de los costeños, porque Bogotá es la única ciudad de importancia económica, política y cultural que se encuentra en tierra fría.

Dada la abundancia en las innovaciones sufijales del español americano ${ }^{10}$ en general, los gentilicios nuevos del español colombiano son sólo una muestra que deberá extenderse a otras regiones de América hispánica.

GARY SCAVNICKY

Wayne State University.

7 Rafari. Srco, Manual de gramática española, 8: ed, Madrid, 1967, p. 126.

${ }^{8}$ Morínicio op. cit., p. 44.

${ }^{9}$ Luis F FóRE., Léxico del cuerpo humano en Colombia, Bogotá, 1969, p. 127.

10 Véase mi tesis Innovaciones en el uso del sufijo en el español de la América Central, Universidad de Illinois, Urbana, 1969. 